\section{HPV vaccine: Can we afford to} hesitate?

To the Editor: Cervical cancer, caused by human papillomavirus (HPV) infection, is highly prevalent in sub-Saharan Africa. The estimated annual incidence of cervical cancer is 35/100 000 women, with 22.5/100 000 associated deaths. This is in stark contrast to the 6.6/100 000 cases and 2.7/100 000 deaths reported in developed countries such as the USA, where HPV vaccination has been available since $2006 .^{[1.2]}$

A vaccine is only approved after extensive clinical trials prove that the benefits of vaccination outweigh any possible risks associated with it. Governmental and non-governmental health organisations scrutinise these clinical trial data through independent medicines review agencies and academic institutions before vaccines are approved and accepted for use (Table 1). Currently, two commercially available HPV vaccines are approved in more than 130 countries, and more than 175 million doses have been distributed worldwide. ${ }^{[3]}$ The USA and Austria in 2006 , Australia, Canada, Belgium, France, Germany and Italy in 2007, and the UK and others in 2008 were among the first countries to introduce HPV vaccination as part of their national immunisation programmes. ${ }^{[2]}$ To date, HPV vaccination has been introduced into national vaccination programmes in at least 40 countries, ${ }^{[4]}$ almost all of which have have lower cervical cancer prevalences than South Africa (SA). ${ }^{[2]}$

The safety of both HPV vaccines has been rigorously tested in clinical trials prior to licensing and as part of ongoing postmarketing surveillance. ${ }^{[2]}$ Data from post-licensure passive, active and population-based epidemiological surveillance studies have not shown any differences in conditions such as Guillain-Barré syndrome, stroke, appendicitis, seizures, allergic reactions, anaphylaxis and venous thromboembolism..$^{[2,5]}$ Reputable global leading health organisations, including the South African HPV Advisory Board, endorse the safety and efficacy of HPV vaccination (Table 1). ${ }^{[6]}$

Both vaccines showed almost $100 \%$ efficacy against precancerous lesions associated with HPV types 16 and 18, which are responsible for around $70 \%$ of cervical cancers. Cross-protection was also reported against some non-vaccine types, which could increase protection to up to $85 \%$ of cervical cancers. ${ }^{[7]}$ Cancer endpoints will take decades to observe, and it would not be ethical to allow women in a placebo arm of a trial to develop cervical cancer. Several proximal measures of vaccine efficacy such as persistent infection with HPV, incidence of cervical precancers and genital warts, and markers of immunogenicity were therefore used in previous studies. These are now accepted by the World Health Organization for use in future vaccine trials as appropriate endpoints that accurately predict vaccine efficacy against cancer. ${ }^{[4]}$ Data from ongoing follow-up studies show that HPV vaccines are effective for at least 9.4 years; levels plateau early and then stay unchanged, so mathematical modelling studies have predicted long-lasting protection for at least 20 years. In addition, antibody levels, and therefore predicted vaccine efficacy, are highest in girls who receive the HPV vaccine at a younger age, providing a strong incentive for early vaccination. ${ }^{[4]}$

It can be expected that antivaccine campaigners will take advantage of the HPV vaccine debate, focusing on concerns about safety and isolated reports of adverse events temporally related to vaccination. It is imperative that healthcare professionals are well informed so they are able to answer questions and dispel the myths surrounding $\mathrm{HPV}$ vaccination in order to ensure maximum vaccine coverage and herd immunity. The National Department of Health and the SA government are applauded for the bold decision to implement and finance this lifesaving initiative. It deserves the full support of all medical professionals!

Submitted on behalf of the following members of the South African HPV Advisory Board: M H Botha, N Cooreman, G Dreyer, N P Godi, F Guidozzi, B Koller, B G Lindeque, C Maske, J Moodley, M Moodley, A Mouton, K L Richter, L Rogers, T Slavik, T Smith, R Soeters, C Turner, K Voyi, J Whittaker and A Williamson.

The SA HPV Advisory Board is an independent group of clinicians and experts with a special interest in HPV-related disease. The Board is affiliated to the SA Society of Gynaecologic Oncology and the SA Society of Obstetricians and Gynaecologists. 
Table 1. Summary of selected leading health organisations that endorse the safety and efficacy of HPV vaccination

Organisation/journal
World Health Organization's Global Advisory Committee on
Vaccine Safety

Vaccine Safety

International Federation of Gynecology and Obstetrics

Global Alliance for Vaccines and Immunisation. Partners include UNICEF, United Nations, Bill \& Melinda Gates Foundation, World Bank

National Cancer Institute, National Institutes of Health, USA

Advisory Committee on Immunization Practices, Centers for Disease Control and Prevention, USA

American College of Obstetricians and Gynecologists

European Medicines Agency, European Union

Medicines and Healthcare Products Regulatory Agency, UK

Joint Committee on Vaccination and Immunisation, UK

Karolinska Institutet, Sweden

Paul Elrich Institut, Agency of the German Federal Ministry of Health

Immunise Australia Program, Australian Government Department of Health and Ageing

National Centre for Immunisation, Research and Surveillance, Australia

Ministry of Health, Malaysia

South African HPV Advisory Board (affiliated to the South African societies of Obstetricians and Gynaecologists and Gynaecological Oncologists)

Cancer Association of South Africa

HPV = human papillomavirus

\section{Available from}

http://www.who.int/wer/2013/wer8829.pdf

http://www.who.int/vaccine_safety/committee/topics/hpv/130619HPV_ VaccineGACVSstatement.pdf

http://www.who.int/immunization/sage/meetings/2014/april/1_HPV_ Evidence_based_recommendationsWHO_with_Appendices2_3.pdf

http://www.figo.org/files/figo-corp/Statement\%20on\%20Safety\%20of\%20 HPV\%20vaccination\%20-\%20FINAL\%20-\%20AUGUST\%202013.pdf

http://www.gavialliance.org/support/nvs/human-papillomavirus-vaccinesupport/

http://www.cancer.gov/cancertopics/factsheet/prevention/HPV-vaccine

http://www.cdc.gov/hpv/vaccine.html

http://www.cdc.gov/hpv/vaccinesafety.html http://www.cdc.gov/vaccines/hcp/ acip-recs/vacc-specific/hpv.html

http://www.acog.org/Resources\%20And\%20Publications/Committee\%20 Opinions/Committee\%20on\%20Adolescent\%20Health\%20Care/Human\%20 Papillomavirus\%20Vaccination.aspx

http://ec.europa.eu/health/sti_prevention/hpv/index_en.htm

http://www.mhra.gov.uk/Safetyinformation/

Generalsafetyinformationandadvice/Product-

specificinformationandadvice/Product-specificinformationandadvice-G-L/ HumanpapillomavirusHPVvaccine/index.htm

http://clinicalvirology.org/ ukcvn/images/stories/aboutus\%20linkspdf/HPV_ JCVI_report_18_07_2008virvacc.pdf

http://ki.se/ki/jsp/polopoly.jsp?d=2637\&a=168933\&l=en\&newsdep=2637

http://www.pei.de/SharedDocs/Downloads/vigilanz/bulletin-zur-arzneimittelsi cherheit/2013/3-2013.pdf?_blob=publicationFile\&v=4

www.australia.gov.au/hpv

http://www.ncirs.edu.au/immunisation/fact-sheets/hpv-humanpapillomavirus-fact-sheet.pdf

http://www.moh.gov.my/attachments/8106

http://www.sasog.co.za/B_HPVPROPHYLACTICVACCINE.asp http://www.sajgo.co.za/index.php/sajgo/article/view/60/pdf_23

http://www.cansa.org.za/files/2013/11/Fact-Sheet-Human-Papilloma-VirusInfection-Cancer-Nov-2013.pdf

\section{K L Richter}

Department of Medical Virology, Faculty of Health Sciences, University of Pretoria and National Health Laboratory Service, Pretoria, South Africa karin.richter@up.ac.za

\section{G Dreyer}

\section{B G Lindeque}

Department of Obstetrics and Gynaecology, Faculty of Health Sciences,

University of Pretoria, South Africa

\section{H Botha}

Department of Obstetrics and Gynaecology, Faculty of Medicine and Health Sciences, Stellenbosch University, Tygerberg, Cape Town, South Africa

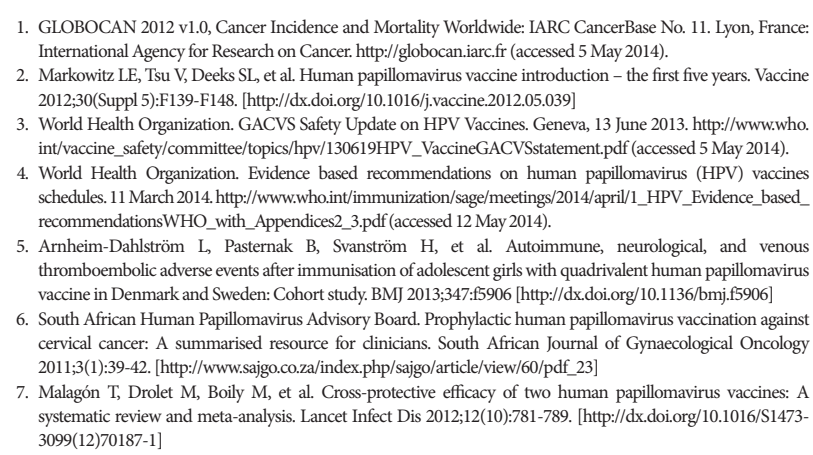

1. GLOBOCAN 2012 v1.0, Cancer Incidence and Mortality Worldwide: IARC CancerBase No. 11. Lyon, France: International Agency for Research on Cancer. http://globocan.iarc.fr (accessed 5 May 2014).

2. Markowitz LE, Tsu V, Deeks SL, et al. Human papillomavirus vaccine introduction - the first five years. Vaccine 2012;30(Supp1 5):F139-F148. [http://dx.doi.org/10.1016/j.vaccine.2012.05.039]

3. World Health Organization. GACVS Safety Update on HPV Vaccines. Geneva, 13 June 2013. http://www.who int/vaccine_safety/committee/topics/hpv/130619HPV_VaccineGACVSstatement.pdf (accessed 5 May 2014). 4. World Health Organization. Evidence based recommendations on human papillomavirus (HPV) vaccines schedules. 11 March 2014. http://www.who.int/immunization/sage/meetings/2014/april/1_HPV_Evidence_based_ recommendationsWHO_with_Appendices2_3.pdf (accessed 12 May 2014).

5. Arnheim-Dahlström L, Pasternak B, Svanström H, et al. Autoimmune, neurological, and venous thromboembolic adverse events after immunisation of adolescent girls with quadrivalent human papillomavirus vaccine in Denmark and Sweden: Cohort study. BMJ 2013;347:F5906 [http://dx.doi.org/10.1136/bmj.f5906]

6. South African Human Papillomavirus Advisory Board. Prophylactic human papillomavirus vaccination against cervical cancer: A summarised resource for clinicians. South African Journal of Gynaecological Oncology 2011;3(1):39-42. [http://www.sajgo.co.za/index.php/sajgo/article/view/60/pdf_23]

7. Malagón T, Drolet M, Boily M, et al. Cross-protective efficacy of two human papillomavirus vaccines: A systematic review and meta-analysis. Lancet Infect Dis 2012;12(10):781-789. [http://dx.doi.org/10.1016/S14733099(12)70187-1]

S Afr Med J 2014;104(8):522-523. DOI:10.7196/SAMJ.8449 